\title{
EFFECTS OF SPINAL TRACTOTOMY ON SPATIAL SEQUENCE RECOGNITION IN MACAQUES ${ }^{1}$
}

\author{
CHARLES J. VIERCK, Jn., ${ }^{2}$ RICHARD H. COHEN, AND BRIAN Y. COOPER \\ Department of Neuroscience and Center for Neurobiological Sciences, University of Florida College of Medicine, Gainesville, \\ Florida 32610
}

Received December 1, 1981; Revised October 7, 1982; Accepted October 8, 1982

\begin{abstract}
Five Macaca speciosa monkeys were trained to discriminate between the order of two tactile stimulus presentations (proximal-distal vs. distal-proximal) to the lateral calf. Psychophysical thresholds for tactile sequence recognition were obtained by varying the distance between the spots stimulated. Stabilized preoperative thresholds for stimulation on the lateral calf averaged $10.4 \mathrm{~mm}$, which is comparable to point localization thresholds for sequential contact of the proximal limbs of humans. Complete interruption of the ipsilateral fasciculus gracilis produced elevations of thresholds within the first 3 postoperative weeks to an average of 3.6 times the control values. With training over 6 postoperative months, normal discrimination recovered. In contrast to the effects of dorsal column (DC) lesions, interruption of the lateral and ventral columns ipsilaterally or contralaterally produced no deficit or a mild and transient deficit.

Monkeys with isolation of either the ipsilateral dorsolateral column (ILC) or the contralateral ventral quadrant (CVQ) exhibited substantial and enduring deficits. Thresholds were elevated an average of 5 times the control values, and recovery was not observed or was incomplete after months of training. In contrast, isolation of the ipsilateral dorsal column produced little or no threshold elevation. The results of isolating lesions complement the series of primary lesions to each cord sector, showing that spatiotactile sequence recognition for the hindlimb is served more critically by the dorsal columns than by the lateral columns.
\end{abstract}

Direct injury to the somatosensory cortex of man, monkeys, cats, and rats has been shown to deteriorate performance on tests of spatiotactile resolution such as two-point discrimination, point localization, obje st recognition, and texture discrimination (Carlson, 1981; Corkin et al., 1970; Finger and Frommer, 1968; Head, 1920; Randolph and Semmes, 1974; Roland, 1976; Semmes et al., 1974; Zubeck, 1952). However, lesions of the dorsal columns have little or no effect on two-point discrimination (Cook and Browder, 1965; Levitt et al., 1966a; Wall and Noordenbos, 1977), object recognition (Schwartz et al., 1972), or texture discrimination (Dobry and Casey, 1972; Kitai and Weinberg, 1968; Schwartz et al., 1972). This discrepancy is puzzling, in view of the physiological characteristics of the dorsal column (DC)-

\footnotetext{
' This work was supported by National Institute of Neurological and Communicative Disorders and Stroke Grant NS 07261 and National Institute of Mental Health Training Grant MH 15735. The technical assistance of Jean Kaufman is gratefully acknowledged. The animals were maintained in animal care facilities fully accredited by the American Association for Accreditation of Laboratory Animal Care.

${ }^{2}$ To whom correspondence should be addressed at Department of Neuroscience, University of Florida College of Medicine, Box J-244 JHMHC, Gainesville, FL 32610.
}

lemniscal system that have led to expectations that DC lesions would deteriorate the clarity of somatosensation when a high degree of spatial and/or temporal resolution is required by the testing situation (Mountcastle, 1961; Vierck, 1978c).

The absence of anticipated impairments of spatiotactile discrimination on the leg following lesion of the fasciculus gracilis (Levitt and Schwartzman, 1966; Vierck, 1973; Vierck and Rand, 1979; Wall and Noordenbos, 1977) can be attributed to intect projections in the lateral columns from topographically arranged dorsal horn cells (Brown and Fuchs, 1975) to the ventrobasal complex of the thalamus (Berkley, 1980; Boivie, 1979, 1980). The ascending spinal projections from the hindlimbs provide a well documented model for relating sensory psychophysics to known physiological characteristics of the spinal pathways (Willis and Coggeshall, 1978). At the present, there is relatively little information on the pattern of afferent sorting in the fasciculus cuneatus, but also there is little evidence favoring a fundamental difference in capacity for spatiotactile coding by the fasciculi gracilis and cuneatus. Both pathways are comprised of primary afferents that are predominantly fast conducting, fast adapting, spatially discrete, somatotopically 
arranged, and synaptically secure (e.g., Pubols and Pubols, 1973; Whitsel et al., 1972). Both fasciculi contain a minor projection from dorsal horn cells receiving convergent inputs from low and high threshold and quickly and slowly adapting afferents (Angaut-Petit, 1975; Rustioni et al., 1979; Uddenberg, 1968), and similar effects of gracilis and cuneatus lesions have been obtained on tests of two-point, texture, and form discrimination (Cook and Browder, 1965; Dobry and Casey, 1972; Kitai and Weinberg, 1968; Levitt and Schwartzman, 1966; Schwartz et al., 1972; Vierck, 1973; Wall and Noordenbos, 1977).

To evaluate the implication that $\mathrm{DC}$ input is not required for spatial coding by the somatosensory cortex, it is instructive to scrutinize the behavioral tasks that have been utilized to test the effects of lesions at cortical and spinal levels. For example, object recognition relies upon a complex array of cues, both proprioceptive and tactile, and compensation for lesion effects often is proportional to the variety of available sources of information. Stimulus objects which differ along many dimensions (e.g., size, shape, weight, and texture and contour number, sharpness, and configuration) can be poor indicators of less than maximal disruption of the discriminative system. Thus, interruption of the dorsal columns produces loss of clemental cues important for object recognition (tactile direction sensitivity: Azulay and Schwartz, 1975; Vierck, 1974; Wall and Noordenbos, 1977; and size discrimination: Vierck, 1973), without eliminating recognition of complex objects (Schwartz et al., 1972).

Texture perception has been tested ordinarily with sandpaper surfaces. But most series of grit sizes and patterns (determined by filter pore sizes, grit materials, and glue thickness) include qualitative sensory changes. That is, a series of sandpapers covaries roughnesssmoothness with attributes such as sharpness that do not reflect spatial frequency alone. Furthermore, textural discriminations of spatial frequency or pattern may be served best by slowly adapting peripheral afferents (Johnson and Lamb, 1981; Phillips and Johnson, 1981) that represent a minor component of the fasciculus gracilis (Whitsel et al., 1972; Angaut-Petit, 1975).

Although two-point discrimination has been utilized for many years as a standard clinical test for dorsal column function, it may be a poor representation of the spatiotactile resolving power of this system (Johnson and Phillips, 1981; Vierck and Jones, 1969). For example, sequential application of a punctate stimulus to the same or different points on the skin produces point localization thresholds that are reliably one-fourth to one-third the values for two-point thresholds from the same skin area (Weinstein, 1968; Zigler, 1935). Sequential application of the punctate stimulus avoids mutual interactions between points, and the task requires differential localization of the stimuli, which is a fundamental operation that is likely to be served by a highly resolved somatotopic map (Loomis and Collins, 1978). Point localization thresholds are elevated by anterior parietal cortex lesions (Corkin et al., 1970), but the results of DC lesions have not been determined. The present study utilized a variant of the point localization task which required the subjects to identify the relative position of as well as the separation between, two skin contacts. This procedure was implemented because of observations that the primary somatosensory cortical map preserves relative positions of points on the body surface, despite gross distortions of the topographic "map" and redundant representations of individual skin loci (Nelson et al., 1980; Werner and Whitsel, 1968).

The purpose of the present study was to determine the contribution of each major, ascending somesthetic pathway to spatiotactile sequence recognition. This can be accomplished, as a first approximation, by lesioning three cord sectors: (1) the ipsilateral dorsal column (IDC; fasciculus gracilis for hindlimb stimulation); (2) the ipsilateral dorsolateral column (ILC), containing the spinocervicothalamic tract and the axons of dorsal horn cells that project to the dorsal column nuclei (Dart and Gordon, 1973; Hazlett et al., 1972; Nijensohn and Kerr, 1975; Rustioni et al., 1979); and (3) the contralateral ventral quadrant (CVQ), encompassing the crossed lateral and ventral spinothalamic tracts. By interrupting each cord sector singly and in combination with each of the other pathways, the sufficiency and necessity of each sector can be defined. The results of the present study distinguish the dorsal columns from the other pathways but do not suggest differences between the ILC and the CVQ in capacity to subserve spatial sequence recognition.

\section{Materials and Methods}

Five adult, female Macaca speciosa monkeys were trained to respond differentially to the spatial order of sequential, localized touch stimuli. The monkeys were housed communally (groups of three to five animals) in outdoor enclosures. They were carried daily to the testing room and placed in a chair that provided loose restraint of the torso and secure placement of the hindlimbs. The animals learned to press either of two spring-loaded doors for food reinforcement (Purina Monkey Chow). The daily ration of food was consumed during and immediately following the testing session; water was offered ad libitum. As training progressed, the monkeys were reinforced only for responding during contact with a $3.2-\mathrm{mm}$ diameter plastic probe within an area of shaved skin on either lateral calf. Then, the animals learned that responses to the left door produced food only following sequential contact with a proximal and then a distal point on the lateral calf. Correct responses to the right door occurred following a distal-proximal sequence of touches within the same area.

Prior to each testing session, the shaved lateral calf of each leg was marked with 11 ink spots that were aligned proximodistally and separated by $5 \mathrm{~mm}$. On a given trial, the experimenter chose two spots and manually applied. the stimulus probe to one and then the other; each contact lasted $1 \mathrm{sec}$, with $1 \mathrm{sec}$ between presentations. If the monkey did not respond by opening a door within 2 sec, the sequence was repeated, for a maximum of three sequences. Responses within the first sequence of a trial or between trials were never reinforced. Incorrect responses during trials terminated the trial (noncorrection procedure). Correct responses were rewarded by handing food through the open door. To avoid fatigue or satiation during testing, sessions were short (100 trials) and approximately one-half of the daily ration of food was consumed during testing. By using a procedure involving forced choice of symmetrical, dichotomized alternatives, 
the percentage of correct responses is a measure of sensitivity that is not influenced by the subjects' decision criteria, unless a subject expresses a response bias to one of the manipulanda. No response biases were observed in the animals after stabilization of the threshold values.

When the monkeys responded correctly on greater than $90 \%$ of the 100 daily trials at a point separation of $50 \mathrm{~mm}$, the procedure was altered in order to track thresholds for spatiotactile sequence recognition by a method of limits by sets procedure (Vierck, 1973). The separation of the stimuli was altered between sets of 50 trials (two sets of 50 trials daily). To minimize habituation, different spots were touched on adjacent trials, but the separation remained fixed within a set of 50 trials. The separation was decreased from $50 \mathrm{~mm}$ in steps of 5 $\mathrm{mm}$ until the animal responded correctly on less than $75 \%$ of 50 trials at a given separation. If less than $75 \%$ correct responses were obtained, then the separation was increased by $5 \mathrm{~mm}$ for the next set. If greater than $75 \%$ correct responses were obtained, then the separation was decreased by $5 \mathrm{~mm}$. Each crossover (of 75\%) defined a threshold estimate. For example, the sequence: $80 \%$ at 10 $\mathrm{mm}, 70 \%$ at $5 \mathrm{~mm}, 74 \%$ at $10 \mathrm{~mm}$, and $76 \%$ at $15 \mathrm{~mm}$, yields two threshold estimates of $7.5 \mathrm{~mm}$ and $12.5 \mathrm{~mm}$. Each monkey was tested preoperatively until threshold performance was stable (see "Results"). A major advantage of the method of limits is that the animals can be maintained at the edge of their competence by tracking thresholds; this should facilitate maximal sensitivity and recovery from sensory defects.

The effects of stimulus intensity and configuration on spatial sequence discrimination were evaluated further by interchanging sets of trials on which the stimulus of touch was accompanied by electrical stimulation. For some animals, the stimulus for one daily set consisted of the $3.2-\mathrm{mm}$ diameter rod, and for the other set, two electrified points ( $2 \mathrm{~mm}$ diameter, $3 \mathrm{~mm}$ separation) were applied to the skin, straddling the appropriate ink spots and oriented mediolaterally. Two milliamperes of constant, $60 \mathrm{~Hz}$ alternating current were passed between the points of the shock probe when in contact with the skin. The sensation evoked by this stimulus to the lateral calf of the experimenters was rated as a single, sharp, well localized, stinging sensation, judged as mildly painful but tolerable for durations beyond $1 \mathrm{sec}$. Thus, the sensation elicited by electrical stimulation was brief and salient, masking the pressure sensation from contact of the points with the skin.

After preoperative thresholds stabilized over a minimum of 25 consecutive estimates, a dorsal laminectomy was performed aseptically, following induction of ketamine and then halothane anesthesia. After reflection of the dura, the cord was visualized through a dissecting microscope, and the lesion was made in an area devoid of surface blood vessels. The lesion was induced by severing small portions of white matter with precision forceps. The dura, muscular layers, and skin were closed with Dexon sutures. The monkeys received postoperative antibiotics and aspirin. Behavioral testing was resumed a minimum of 1 week following surgery.

After completion of the behavioral experiment, the animals received an overdose of Nembutal and were perfused through the heart with normal saline, followed by $10 \%$ formalin. The spinal cord was removed from $\mathrm{C} 1$ through several segments below the most caudal lesion, and the level of each lesion was determined. Alternate, celloidin-embedded, $30-\mu \mathrm{m}$ sections were stained with Weil or thionin, to reveal absence of intact fibers and gliosis within the lesioned segments of spinal cord. The extent of each lesion was determined with camera lucida drawings of sections throughout the area of scar tissue and both rostral and caudal to the lesion. The lesion border in each drawing corresponded to the larger extent of neural damage detectable on adjacent sections. Similarly, the representative drawing was selected on the basis of the largest lesion extent.

\section{Results}

Normal discrimination of spatial sequence on the hairy skin of monkeys' hindlimbs. The mean preoperative threshold for the five monkeys was $10.4 \mathrm{~mm}$ (SD = \pm 2.0 ; range $=6.7$ to $13.3 \mathrm{~mm}$ ). This value is comparable to human thresholds for point localization on the proximal extremities; for example, point localization thresholds of $10 \mathrm{~mm}$ have been reported for the lateral calf of humans (Weinstein, 1968; Zigler, 1935). The point localization test requires only that the subjects detect the points stimulated as different; identification of the spatial sequence of skin contacts is not required. In comparing threshold values between the present studies and related investigations in humans, it should be noted that the monkey subjects were highly practiced, while the human subjects were relatively unpracticed with stimulation within a given body rcgion. Previous investigations have shown that spatiotactile thresholds can decrease markedly with extensive practice (Dressler, 1894; Jones et al., 1973). Thus, the preoperative control values for the present study can be regarded as stabilized threshold estimates that reflect optimum acuity for the region stimulated.

Three monkeys (nos. 1, 2 and 3; Fig. 1) were stimulated on alternate sets of 50 trials with a plastic probe or with bipolar electrical stimulation. Spatiotactile sequence thresholds were unaffected by the presence of electrical stimulation, either before or after spinal cord lesions that produced mild to severe deficits.

Ipsilateral dorsal column lesions. Figure 1 presents pre- and postoperative spatiotactile sequence thresholds (averaged over five consecutive threshold estimates) as they vary over long periods of testing. Monkeys 4 and 5 received complete lesions of the fasciculus gracilis, the first (I) on one side and the second (II) on the other (Fig. 1; 4IR, 4IIL; 5IL, 5IIR; L = left and $\mathrm{R}=$ right side of the cord). All four lesions produced substantial deficits in the immediate postoperative periods. Initial postoperative thresholds varied from 21.5 to $37.5 \mathrm{~mm}$; the average of the first-block threshold values was $32 \mathrm{~mm}$, or 3.6 times the control thresholds for these monkeys. The initial deficit was alleviated by postoperative training that continued for an average of 160 calendar days (range of 122 to 217 days) or 4100 trials. Figure $2 A$ presents the beginning and end points of this recovery process by displaying differences in postoperative and control thresholds, averaged over the first three blocks of estimates in each 


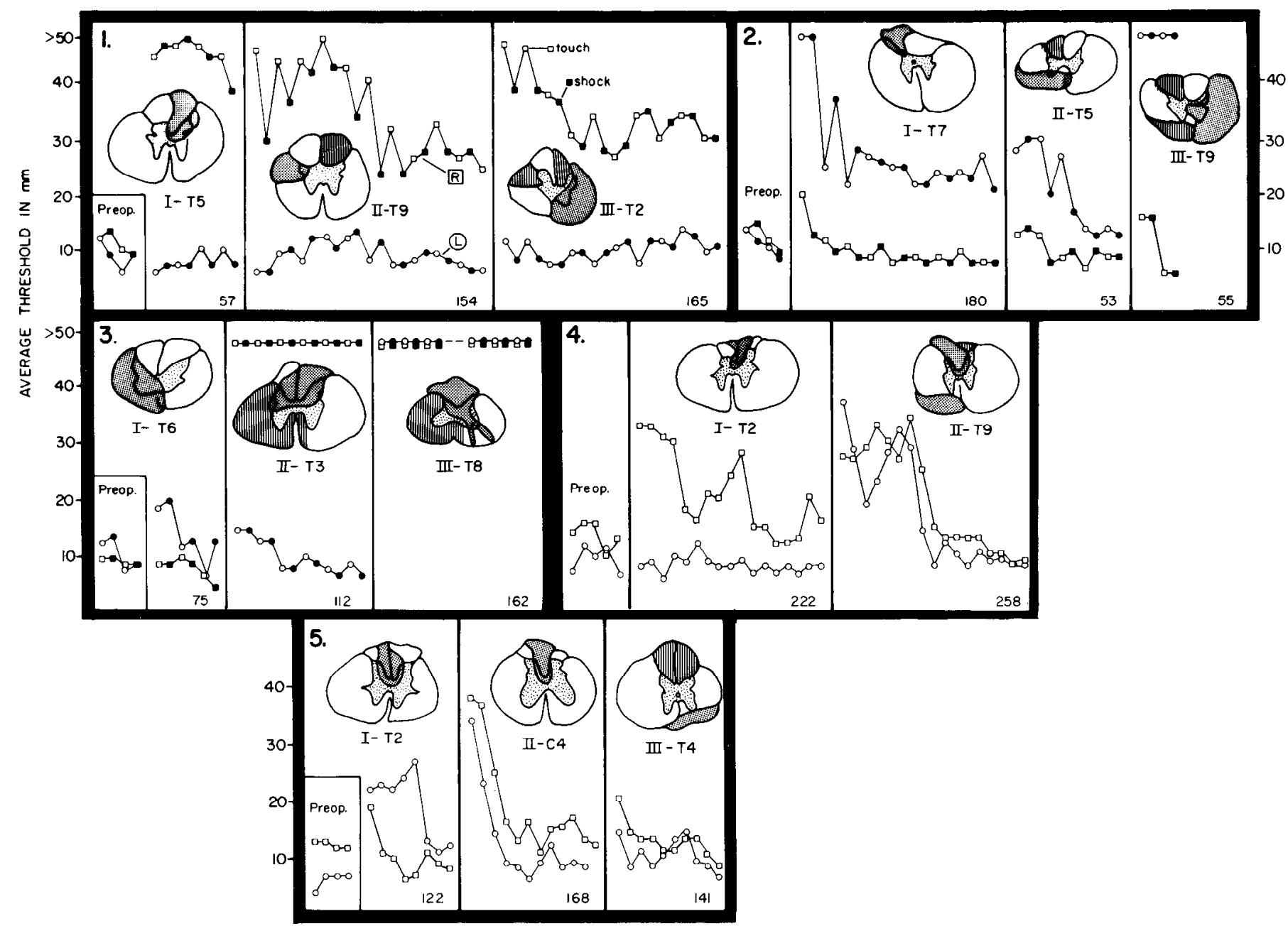

BLOCKS OF 5 THRESHOLDS

Figure 1. The time course of threshold changes before and following sequential spinal cord lesions (I, II, or III) is shown for each of five monkeys (nos. 1 to 5). Individual points represent average threshold values obtained from five successive threshold estimates (see "Materials and Methods"). $\bigcirc$, : thresholds from the left leg; $\square, \square$ : thresholds from the right leg. The open symbols represent tactile stimulation with a plastic probe; the closed symbols represent tactile, bipolar electrical stimulation. A diagram obtained from camera lucida drawings of each lesion is given in the panel with data obtained following that lesion. The most recent lesion for each postoperative period is indicated by stippling; lesions administered previously are indicated by vertical lines. The left side of the spinal cord is on the reader's left. The level of each lesion is given below the lesion diagram. The successive postoperative periods are identified by Roman numerals. The last four blocks of stabilized preoperative thresholds are plotted, and each postoperative block of five threshold estimates is presented. The number of calendar days elapsed between surgery and the last threshold estimate in a postoperative period is indicated in the bottom right of each panel.

postoperative period (early testing period) and over the last five threshold blocks within the relevant postoperative period (late testing period). These histograms illustrate consistency in the magnitude of the partial deficit and full recovery following each lesion. Primary lesions to the ipsilateral dorsal column (IDC) of monkeys 1 and 2 partially involved the ipsilateral lateral column (ILC), and the recovery period was prolonged beyond that of animals 4 and 5 , with lesions clearly confined to the DC, (Fig. 1). Camera lucida drawings of the area of demyelination in sections just rostral to the dorsal column lesions are shown in Figure 3.

Isolation of the ipsilateral dorsal column. Two monkeys received a sequence of lesions that isolated one dorsal column by interrupting the ipsilateral dorsolateral column and all contralateral white matter of the cord
(1IIIL; Figs. 1 and $2 B$ ) or the ipsilateral lateral and ventral columns and the contralateral ventral quadrant (2IIIR; Figs. 1 and 2B). These two methods of DC isolation were employed because of the importance of preserving the health of the monkeys, by sparing a portion of either lateral or ventral column. Neither the ipsilateral ventral quadrant nor the contralateral dorsal quadrant is thought to contain major ascending pathways contributing to "conscious" somatosensation, and preservation of either sector contributes significantly to the maintenance of vital somatic and autonomic functions below the series of lesions. Both monkeys exhibited excellent discrimination in the early period of postoperative testing, demonstrating the sufficiency of the dorsal columns for supporting high resolution spatial discrimination. 


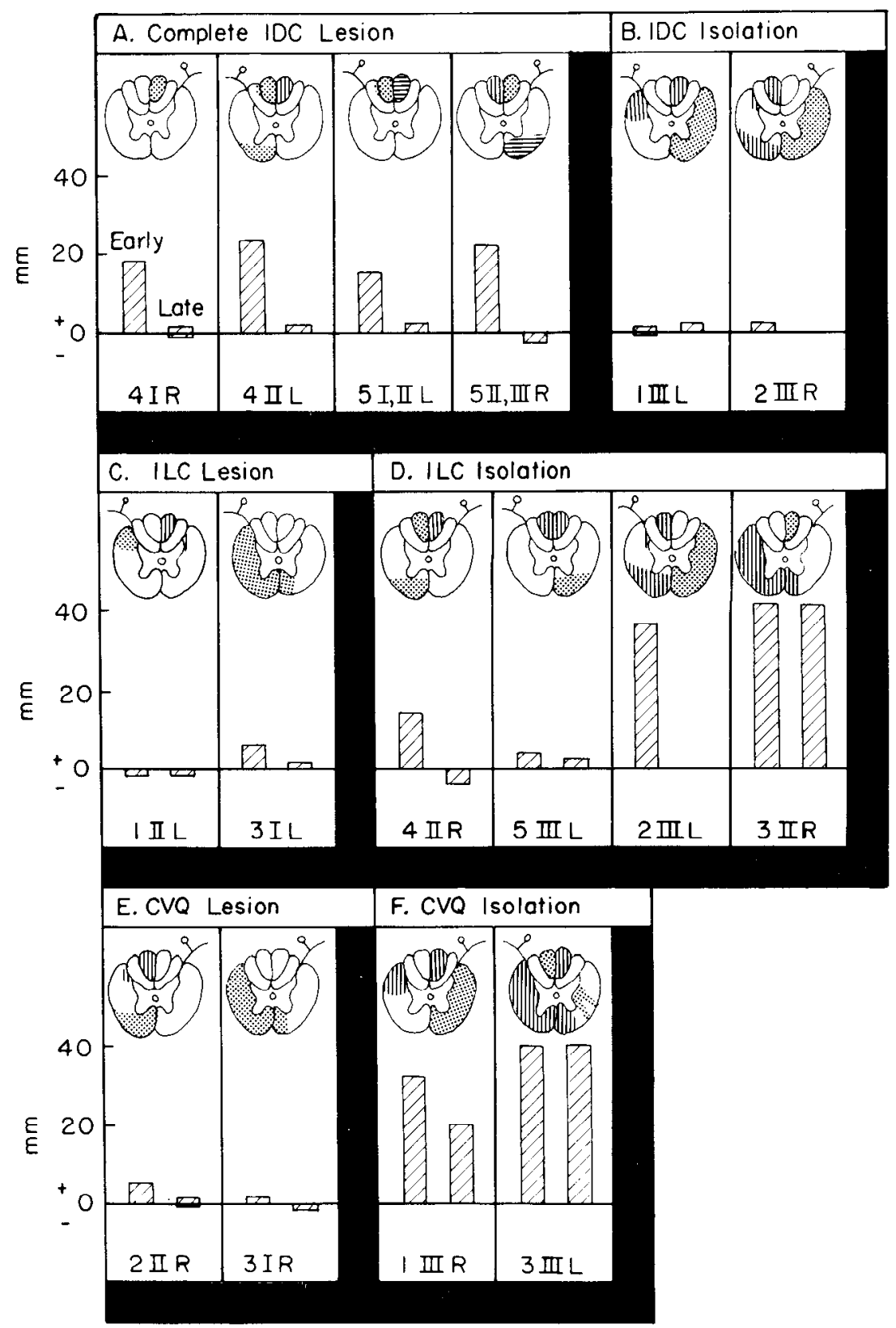

Figure 2. Each example of lesions that interrupt or isolate the ipsilateral dorsal column (IDC), the ipsilateral lateral column (ILC; particularly the dorsolateral column), or the contralateral ventral quadrant (CVQ) is indicated on a standardized representation of the spinal cord. Stippling indicates a standardized representation of the lesion immediately preceding the early postoperative data given in the panel. Vertical lines depict previous lesions, and horizontal lines fill in regions lesioned during recovery from the stippled lesion. The leg from which the plotted data were obtained is indicated by the representation of the dorsal root on the right or left of the drawing. Threshold differences between lesion and control conditions for the given animal and limb are shown. Early postoperative thresholds are averaged from the first three postoperative blocks (15 estimates). Late postoperative thresholds are averaged from the last five blocks in the appropriate postoperative period. The animal number, postoperative period(s), and leg tested are indicated at the bottom of each panel. Absence of a bar indicates lack of available data (2III, late).

Lesions of the ipsilateral dorsolateral column. Lesion II of monkey 1 and lesion I of monkey 3 severed the ipsilateral dorsolateral column (IDLC) and spared the IDC and the contralateral ventral quadrant. The larger lesion (3IL; Figs. 1 and $2 C$ ), involving all of the left lateral column and both ventral columns, produced a mild initial deficit (a maximum of 1.8 times the control threshold), with recovery to preoperative values at 26 postoperative days (550 trials). The other, smaller lesion, confined to the left dorsolateral column, produced no significant deficit (1IIL; Figs. 1 and $2 C$ ).

Isolation of the ipsilateral dorsolateral column. Two monkeys received lesions of the fasciculus gracilis $(100 \%)$ and much of the contralateral ventral quadrant (4IIR; 5IIIL; Figs. 1 and $2 D$ ). In both of these cases, the ventral quadrant lesions were incomplete (did not extend dorsally to the dentate ligament). The ventral lesions followed recovery from the dorsal column lesions, and max- 

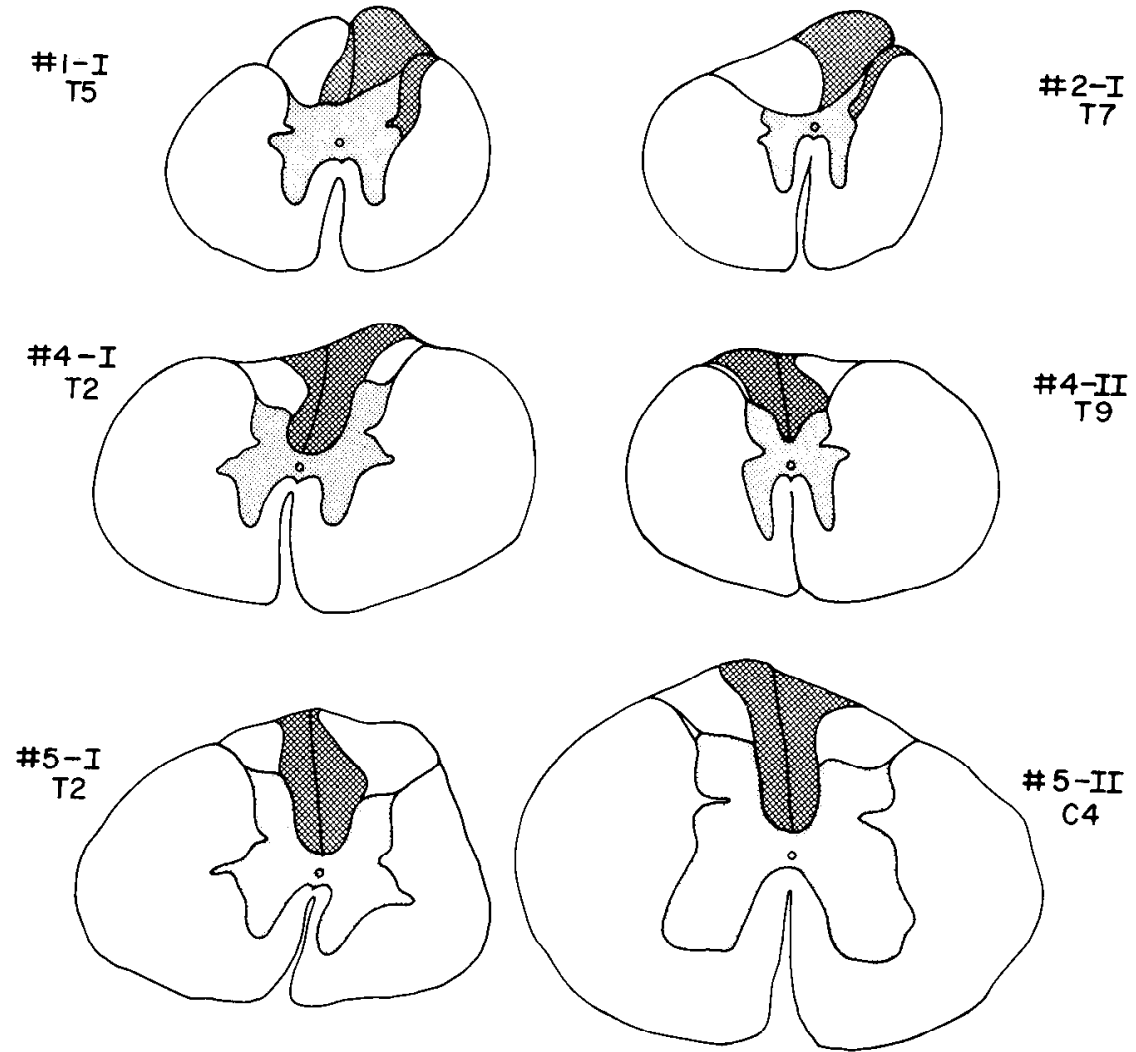

Figure 3. Camera lucida drawings of demyelinated areas of white matter on Weil-stained sections just rostral to the dorsal column lesions, permitting tracing of the dorsal horns. These drawings provide conservative estimates of the area of white matter involved, but incidental interruption of the lateral column (\#1I and \#2I) can be identified with certainty. Small portions of one fasciculus gracilis were spared by the first lesion received by two animals (\#4IL; \#5IR) and discrimination was unaffected (\#4) or briefly elevated (\#5). Complete lesions of the fasciculus gracilis that were confined to the dorsal columns produced similar deficits and recovery (Fig. 2A), and lesions that extended into the ILC produced larger deficits and prolonged (\#2I, IIL) or incomplete (\#1I, IIR) recovery (see Fig. 1).

imal threshold elevations of $15 \mathrm{~mm}(2.1$ times control values: $4 \mathrm{IIR})$ and $7 \mathrm{~mm}$ (2.0 times control values: $5 \mathrm{IIIL})$ were observed, but full recovery occurred with practice over 3 to 4 postoperative months.

One monkey received a complete lesion of the right DC following complete interruption of the left lateral and ventral columns (3IIR; Figs. 1 and $2 D$ ). A severe and enduring deficit of $40 \mathrm{~mm}$ resulted from the second lesion. Similarly, isolation of the left dorsolateral column of monkey 2 produced a substantial deficit of $36 \mathrm{~mm}$ following interruption of the IDC and then the contralateral lateral and ventral columns; in this case, recovery from the ipsilateral DC lesion had occurred before the final, isolating lesion (2IIIL; Figs. 1 and 2D).

Lesions of the contralateral ventral quadrant. Two monkeys received lesions which spared the ipsilateral dorsal quadrant but severed most or all of the contralateral ventral quadrant. A small and transient threshold elevation of 1.8 times the control threshold, with recovery by 23 days, occurred contralateral to a lesion restricted to the ventral quadrant (2IIR; Figs. 1 and $2 E$ ). Complete interruption of the left lateral and ventral columns produced no deficit on the right leg in the other monkey (3IR; Figs. 1 and $2 E$ ).

Isolation of the contralateral spinal pathways. Following ipsilateral hemisection and a contralateral lesion of the dorsolateral column (isolating the contralateral ventral quadrant), a severe and enduring deficit was observed (1IIIR; Figs. 1 and $2 F$ ). The maximal deficit was 4 times the control values, and following 165 days of postoperative testing the threshold remained at $31.7 \mathrm{~mm}$. A similar result was obtained (3IIIL; Figs. 1 and $2 F$ ) following an ipsilateral hemisection (plus lesion of the contralateral DC and several "fingers" of lateral column infarction). Thresholds were elevated to $47.5 \mathrm{~mm}$ over 162 postoperative days.

Lesion sequences. Table I summarizes the effects and conclusions from primary lesions to each cord sector and from the most complete isolating lesions. Threshold values are listed in parentheses for the early postoperative period (initial deficit) and following recovery from primary lesions and after the last of each isolating sequence of lesions. The degree of recovery with retraining is indicated for each type of lesion, and the sufficiency and necessity of each cord sector (or combination of sectors) for normal levels of discrimination are stated. To evaluate the possibility that the results of sequential, isolating lesions could depend uniquely upon the occurrence of a recovery process initiated by a particular primary lesion, each sector was isolated by both possible orders of lesion to the other pathways. The order of these sequential lesions did not determine the occurrence of deficits from the second lesion. Isolation of the IDC produced little or no deficit, regardless of whether the ILC or the CVQ was 
TABLE I

Effects of primary and isolating spinal cord lesions

\begin{tabular}{|c|c|c|c|}
\hline Lesion & $\begin{array}{l}\text { Initial Deficit } \\
\text { (threshold) }\end{array}$ & $\begin{array}{c}\text { Recovery } \\
\text { (threshold) }\end{array}$ & Interpretation \\
\hline \multicolumn{4}{|c|}{ Primary lesions } \\
\hline IDC & $\begin{array}{l}\text { Substantial } \\
(32.0 \mathrm{~mm})\end{array}$ & $\begin{array}{l}\text { Total } \\
(9.1 \mathrm{~mm})\end{array}$ & $\begin{array}{l}\text { The IDC is important } \\
\text { but not necessary } \\
\text { (after recovery) }\end{array}$ \\
\hline ILC & $\begin{array}{l}\text { Slight } \\
(12.5 \mathrm{~mm})\end{array}$ & $\begin{array}{l}\text { Total } \\
(7.6 \mathrm{~mm})\end{array}$ & $\begin{array}{l}\text { Neither the ILC nor } \\
\text { the CVQ is neces- } \\
\text { sary }\end{array}$ \\
\hline CVQ & $\begin{array}{l}\text { Slight } \\
(10.5 \mathrm{~mm})\end{array}$ & $\begin{array}{l}\text { Total } \\
(7.5 \mathrm{~mm})\end{array}$ & \\
\hline \multicolumn{4}{|c|}{ Isolating lesions } \\
\hline $\begin{array}{l}\text { ILC then } \\
\text { CVQ }\end{array}$ & $\begin{array}{l}\text { None } \\
(11.5 \mathrm{~mm})\end{array}$ & $\begin{array}{l}\text { Total } \\
(11.5 \mathrm{~mm})\end{array}$ & $\begin{array}{l}\text { The ILC and CVQ } \\
\text { are not necessary }\end{array}$ \\
\hline $\begin{array}{l}\text { CVQ then } \\
\text { ILC }\end{array}$ & $\begin{array}{l}\text { Slight } \\
(13.5 \mathrm{~mm})\end{array}$ & $\begin{array}{l}\text { Total } \\
(5.5 \mathrm{~mm})\end{array}$ & $\begin{array}{l}\text { The dorsal columns } \\
\text { are sufficient }\end{array}$ \\
\hline $\begin{array}{l}\text { IDC then } \\
\text { CVQ }\end{array}$ & $\begin{array}{l}\text { Severe } \\
(>47.5 \mathrm{~mm})\end{array}$ & Not tested & $\begin{array}{l}\text { The IDC and either } \\
\text { the ILC or the } \\
\text { CVQ is necessary }\end{array}$ \\
\hline $\begin{array}{l}\text { CVQ then } \\
\text { IDC }\end{array}$ & $\begin{array}{l}\text { Severe } \\
(>47.5 \mathrm{~mm})\end{array}$ & $\begin{array}{l}\text { None } \\
(>47.5 \mathrm{~mm})\end{array}$ & \\
\hline $\begin{array}{l}\text { IDC then } \\
\text { ILC }\end{array}$ & $\begin{array}{l}\text { Severe } \\
(46.5 \mathrm{~mm})\end{array}$ & $\begin{array}{l}\text { Slight } \\
(31.7 \mathrm{~mm})\end{array}$ & $\begin{array}{l}\text { Neither the ILC nor } \\
\text { the CVQ is suffi- } \\
\text { cient }\end{array}$ \\
\hline $\begin{array}{l}\text { ILC then } \\
\text { IDC }\end{array}$ & $\begin{array}{l}\text { Severe } \\
(>47.5 \mathrm{~mm})\end{array}$ & $\begin{array}{l}\text { None } \\
(>47.5 \mathrm{~mm})\end{array}$ & \\
\hline
\end{tabular}

the first to be lesioned. Isolation of either the ILC or the CVQ produced substantial and enduring deficits, regardless of whether the IDC or the other lateral column was interrupted first.

\section{Discussion}

Spatiotactile resolution has been viewed classically as a sensory attribute subserved exclusively by the dorsal columns, because of a topographic organization that begins with a rich supply of afferents with small receptive fields (RFs). Even though a substantial portion of DC afferents (slowly adapting and deep units) exit the dorsal columns to synapse in the dorsal horn (Petit and Burgess, 1968), the fasciculus gracilis forms a detailed and coherent "map" of the hindlimb in its rostral progression (Whitsel et al., 1972). In the absence of the fasciculus gracilis, the population of responding cells in a core region of the primary somatosensory cortex is greatly reduced (Dreyer et al., 1974). The topographic ordering of thalamic projections from either the spinothalamic or the spinocervicothalamic pathways appears to be less precise than the DC-lemniscal projection (Boivie, 1978, 1979,1980 ), but convergent projections to fringe zones of the dorsal column nuclei (Beck, 1976a; Gordon and Jukes, 1964; Hand and Van Winkle, 1977) and the ventrobasal complex (Berkley, 1980; Spreafico et al., 1981) provide spatially ordered inputs to the SI and SII somatosensory cortical areas.

The consequences of fasciculus gracilis lesions for tactile sequence recognition support a critical role for the dorsal columns in spatial resolution. In contrast to the classical two-point test, which is not elevated significantly by DC lesions affecting the arms or the legs (Cook and Browder, 1965; Levitt and Schwartzman, 1966; Wall and Noordenbos, 1977), sequence recognition reveals sig- nificant early postoperative deficits. However, spatial sequence thresholds were elevated submaximally by DC lesions, indicating that other pathways normally contribute to spatial order and coding by the somesthetic systems. The recovery process following DC lesions took the form of an early plateau (average sequence threshold of 3.7 times the control values), followed by a decrease in thresholds, beginning from several weeks to several months following surgery (500 to 2500 trials) and involving a long period of retraining that brought thresholds to normal levels. The onset of recovery may reflect the occurrence of collateral sprouting, which occurs optimally in convergent projection systems (Goldberger and Murray, 1978) such as the ventrobasal fringe that is partially deafferented by a DC lesion. The entire recovery process required approximately 6 months. A similarly long time course of recovery has been observed with roughness discrimination following SI cortical lesions (Finger and Reyes, 1975). In this case, as with DC lesions (Vierck, 1982), improvement depended on task-specific practice and was not related to time per se. The recovery of sequence recognition should not be considered restricted to proximal loci that are less densely supplied by the dorsal columns than distal areas, since a similar deficit and recovery to preoperative levels has been demonstrated for threshold discrimination of the size of discs impressed on the glabrous skin of the feet (Vierck, 1973).

It appears that a number of aspects of purely spatial resolution are trivial and/or extremely secure functions of the somatosensory systems; these spatial attributes relate to edge or point contours and their absolute location (Vierck and Rand, 1979), absolute separation (Cook and Browder, 1965; Levitt and Schwartzman, 1966), relative separation (Vierck, 1973), and relative location (present study). Theoretical accounts of the minimal information required for these functions indicates that innervation density is more critical than receptive field size (Erickson, 1968); hence lateral column projection cells with a large range of receptive field sizes can compensate for a massive deafferentation by DC lesion and can contribute a high degree of spatial resolution.

The recovery from DC lesions of purely spatiotactile thresholds contrasts with studies in which spatiotemporal somatosensory coding has been evaluated. Discrimination of the direction of movement of a stimulus across the skin surface is lost "permanently" after DC section (Azulay and Schwartz, 1975; Vierck, 1974; Wall and Noordenbos, 1977), and the critical feature in these tasks may be the spatial progression of the stimulus in time. Also, spatially precise motor movements can be slowed when the target is located visually and the responding arm or leg is affected by the DC lesion (Beck, 1976b; Vierck, 1978a). These comparisons suggest that the unique functions of the DC-lemniscal system pertain to the combination of precise spatial and temporal resolution.

Several previous attempts to isolate the dorsal columns have used a difficult preparation, involving section of all spinal white matter except the dorsal columns (Frommer et al., 1977; Myers et al., 1974). These animals detected the presence of electrical stimulation or touch involving segments below the section. The present results and Levitt and co-workers' studies of two-point and limb position discriminations (M. Levitt, C. J. Vierck, J. Ovelmen-Levitt, and R. J. Schwartzman, unpublished obser- 
vations) have revealed excellent spatial senses of touch and proprioception following virtual isolation of the dorsal columns. That is, the isolating lesions were administered sequentially, and some portion of one lateral column was spared: either the ipsilateral ventral quadrant or the contralateral dorsolateral column. These monkeys are not difficult to maintain in good health, and the cord sectors below the lesions should not be served by task-relevant, long ascending pathways from the dorsal horn to the thalamus (with the exception of a contribution to the dorsal columns; Rustioni et al., 1979).

Animals with DC-isolating lesions were capable of the many skills involved in psychophysical testing: attention to relevant cues, recollection of tactile and proprioceptive perceptions, discrimination of body positions and positions of stimuli on the body, and a form of sensory-motor integration. Although there was a severe loss of input to the reticular formation, from interruption of the spinothalamic and spinoreticular tracts, the animals' discrimination and attention to the task were excellent. Monkey no. 2 is an important example (2IIIR; Fig. $2 B$ ), because the spinoreticular tracts were interrupted to a large extent contralaterally, in conjunction with total ipsilateral section. The excellent performance of this monkey contrasts with the relatively debilitating effects of interrupting all non-DC spinal pathways at one level (Frommer et al., 1977; Myers et al., 1974) or lesioning the reticular formation directly (Sprague et al., 1963). Complete interruption of the lateral and ventral columns at one level and at one time produces especially profound deafferentation of the brain stem by eliminating conduction via the propriospinal system (Basbaum, 1973; Breazile and Kitchell, 1968), and this could contribute to differences in performance of animals with simultaneous vs. sequential lesions of the lateral and ventral columns. Given their ability to attend to and perform the task, our DC isolates demonstrate spatial capacities that have been ascribed to the dorsal columns (Mountcastle, 1961) but have been questioned by the lack of impairment often seen with DC lesions (reviewed by Beck, 1976a; Kruger and Norton, 1973; Norrsell, 1980; Vierck, 1978b, c; Wall, 1970). This finding demonstrates the necessity of observing the effects of lesion and isolation of each spinal pathway for interpretation of their functional contributions.

The ipsilateral dorsolateral columns have received much attention, in relation to apparent redundancy with the DC-lemniscal system for touch and with the spinothalamic tracts for pain. Although the spinocervicothalamic tract is thought to share lemniscal functions with the dorsal columns (e.g., discriminative touch; Kitai and Weinberg, 1968; Norrsell, 1966; Tapper, 1970) in carnivores, its anatomical prominence and physiological potency are thought to decrease relative to the spinothalamic tract in primates, including man (Andersson et al., 1975; Truex et al., 1965). However, the functional importance of these pathways cannot be deduced from their structural and physiological properties or generalized across different sensory tests. Psychophysical studies of primates have shown either that the ILC is more important than the CVQ for two-point discrimination ( $M$. Levitt, C. J. Vierck, and R. J. Schwartzman, unpublished observations) or that the two scetors appear equivalent (present study).

Combined section either of the IDC and the ILC or of the fasciculus gracilis and the spinothalamic tracts produced large, enduring deficits of tactile sequence recognition. Normal thresholds for sequence discrimination required a somesthetic system supplied either by the dorsal columns or by both lateral columns. Thus, dorsal horn cells that project long axons via the lateral columns to the specific, thalamocortical, somesthetic system appear to form a coherent spatial representation of the body surface that is able to compensate for absence of the dorsal columns but is not crucial, in whole or in part, for normal discrimination, in the presence of the dorsal columns. Primary lesion of one lateral column does not produce ipsilateral or contralateral elevations of sequence thresholds or deficits on any purely sensory test for spatiotactile discrimination that has been utilized in primates. However, in the absence of the dorsal columns, recognition of the relative location of tactile stimuli is sensitive to interruption of either lateral column. The interdependence of the lateral column pathways for tactile localization (following DC lesion) is reasonable, considering the extensive interdigitation of their projections to the thalamic ventrobasal complex (Berkley, 1980).

The present analysis has concentrated attention on the lemniscal-thalamic and the spinothalamic projection systems. Effects of spinal lesions on descending projections may also contribute to the effects observed. For example, a descending, dorsolateral system exerts inhibitory actions on dorsal horn neurons (Brown et al., 1973; Fetz, 1968; Holmquist et al., 1960; McCreery et al., 1979; Willis, 1979), and the threshold elevations produced by dorsal quadrant lesions could have resulted from increased "noise." However: (1) inhibitory effects of the raphe-spinal component of the dorsolateral pathway are exerted predominantly on input to the dorsal horn from high threshold nociceptors (Basbaum and Fields, 1980; Duggan and Griersmith, 1979; Rivot et al., 1980), and (2) when the ipsilateral dorsal column was intact, complete, bilateral IDLC lesions did not elevate thresholds (1IIIL; Fig. $2 B$ ).

The ipsilateral ventral quadrant contains ascending spinoreticular tracts and also descending, noradrenergic tracts that modulate transmission through the dorsal horn (Belcher, 1977; Headley et al., 1978; Hodge et al., 1981). These pathways exert bilateral effects at their rostral or caudal terminations, and therefore the assessment of ipsilateral or contralateral ventral quadrant (VQ) section can indicate influences of the spinoreticular and reticulospinal tracts. Little or no discernible effects could be attributed to the following additions of spinoreticular and reticulospinal section to other lesions: (1) ipsilateral VQ and DC (2IIL; 4IIL; 5IIIR; Fig. 1); (2) ipsilateral VQ and DLC (3IL; Fig. 2C); (3) contralateral VQ, the ipso facto confounding of spinoreticular and spinothalamic section, producing no deficit (2IIR, 3IR; Fig. 2E); and (4) bilateral VQ with ipsilateral DLC (2IIIR; Fig. 2B). Apparently the spinal-reticular-spinal system in the ventral cord is more relevant to pain conduction than to coding of discriminative touch. Ventral hemisection, interrupting most or all of the spinal-reticular-spinal projections systems, produces permanent attenuation of pain reactivity (Vierck and Luck, 1979) but does not disrupt tactile sequenec recognition (2IIIR; Fig. $2 B$ ).

In summary, psychophysical thresholds for tactile sequence recognition implicate two systems that are capa- 
ble of mediating resolution of punctate stimuli. Isolation of the DC-lemniscal system forces the monkeys to rely upon input from quickly adapting tactile receptors. The DC-lemniscal system supports spatiotactile resolution securely, as evidenced by a lack of effects (even temporarily) from $\mathrm{DC}$ isolation. Isolation of the dorsal horn projections in the lateral columns by DC lesions produces substantial early deficits, but discriminative capacity returns to normal levels with extensive postoperative testing. The predominant source of tactile input to the lateral column pathways comes from slowly adapting receptors (Brown, 1981; Willis et al., 1974). Thus, the relative location of punctate stimuli can be subserved by spinal projection systems supplied predominantly by either quickly or slowly adapting receptors. The latter system of projections from the dorsal horn supports tactile sequence recognition only if both lateral columns are intact.

\section{References}

Andersson, S. A., S. Finger, and U. Norrsell (1975) Cerebral units activated by tactile stimuli via a ventral spinal pathway in monkeys. Acta Physiol. Scand. 93: 119-128.

Angaut-Petit, D. (1975) The dorsal column system. II. Functional properties and bulbar relay of the postsynaptic fibres of the cat's fasciculus gracilis. Exp. Brain Res. 22: 471-493.

Azulay, A., and A. S. Schwartz (1975) The role of the dorsal funiculus of the primate in tactile discrimination. Exp. Neurol. 46: 315-332.

Basbaum, A. I. (1973) Conduction of the effects of noxious stimulation by short-fiber multisynaptic systems of the spinal cord of the rat. Exp. Neurol. 40: 699-716.

Basbaum, A. I., and H. L. Fields (1980) Pain control: A new role for the medullary reticular formation. In The Reticular Formation Revisited, J. A. Hobson and M. A. B. Brazier, eds., pp. 329-348, Raven Press, New York.

Beck, C. H. M. (1976a) Dual dorsal columns: A review. Can. J. Neurol. Sci. 3: 1-9.

Beck, C. H. M. (1976b) Forelimb performance by squirrel monkeys (Saimiri sciureus) before and after dorsal column lesions. J. Comp. Physiol. Psychol. 90: 353-362.

Belcher, G. (1977) Correlation between effects of brain stem stimulation and effects of serotonin and noradrenalin on nonnocioceptive and nocioceptive spinal neurons. Br. J. Pharmacol. 61: 149-150.

Berkley, K. J. (1980) Spatial relationships between the terminations of somatic sensory and motor pathways in the rostral brainstem of cats and monkeys. I. Ascending somatic sensory inputs to lateral diencephalon. J. Comp. Neurol. 193: 283317.

Boivie, J. (1978) Anatomical observations on the dorsal column nuclei, their thalamic projection and the cytoarchitecture of some somatosensory thalamic nuclei in the monkey. J. Comp. Neurol. 178: 17-48.

Boivie, J. (1979) An anatomical reinvestigation of the spinothalamic tract in the monkey. J. Comp. Neurol. 186: 343-370.

Boivie, J. (1980) Thalamic projections from lateral cervical nucleus in monkey. A degeneration study. Brain Res. 198: $13-26$.

Breazile, J. E., and R. L. Kitchell (1968) A study of fiber systems within the spinal cord of the domestic pig that subserve pain. J. Comp. Neurol. 133: 373-382.

Brown, A. G. (1981) Organization in the Spinal Cord. The Anatomy and Physiology of Identified Neurons, SpringerVerlag, New York.

Brown, A. G., E. J. Kirk, and H. F. Martin (1973) Descending and segmental inhibition of transmission through the spinocervical tract. J. Physiol. (Lond.) 230: 689-705.
Brown, P. B., and J. L. Fuchs (1975) Somatotopic representation of hindlimb skin in cat dorsal horn. J. Neurophysiol, 38: 1-9.

Carlson, M. (1981) Characteristics of sensory deficits following lesions of Brodmann's areas 1 and 2 in the post central gyrus of Macaca mulatta. Brain Res. 204: 424-430.

Cook, A. W., and F. J. Browder (1965) Function of posterior columns in man. Arch. Neurol. Psychiat. 12: 72-79.

Corkin, S., B. Milner, and T. Rasmussen (1970) Somatosensory thresholds: Contrasting effects of postcentral-gyrus and posterior parietal-lobe excisions. Arch. Neurol. 23: 41-58.

Dart, A. M., and G. Gordon (1973) Some properties of spinal connections of the cat's dorsal column nuclei which do not involve the dorsal columns. Brain Res. 58: 61-68.

Dobry, P. J. K., and K. L. Casey (1972) Roughness discrimination in cats with dorsal column lesions. Brain Res. 44: 385397.

Dressler, F. B. (1894) Studies on the psychology of touch. Am. J. Psychol. 6: 313-368.

Dreyer, D. A., R. J. Schneider, C. B. Metz, and B. L. Whitsel (1974) Differential contributions of spinal pathways to body representation in postcentral gyrus of Macaca mulatta. J. Neurophysiol. 37: 119-145.

Duggan, A. W., and B. T. Griersmith (1979) Inhibition of the spinal transmission of nociceptive information by supraspinal stimulation in the cat. Pain 6: 149-161.

Erickson, R. P. (1968) Stimulus coding in topographic and nontopographic modalities: On the significance of the activity of individual sensory neurons. Psychol. Rev. 75: 447-465.

Fetz, E. E. (1968) Pyramidal tract effects on interneurons in the cat lumbar dorsal horn. J. Neurophysiol. 31: 69-80.

Finger, S., and G. P. Frommer (1968) Effects of cortical lesions on tactile discriminations graded in difficulty. Life Sci. 7: 897-904.

Finger, S., and R. Reyes (1975) Long-term deficits after somatosensory cortical lesions in rats. Physiol. Behav. 15: 289-293.

Frommer, G. P., B. R. Trefz, and K. L. Casey (1977) Somatosensory function and cortical unit activity in cats with only dorsal column fibers. Exp. Brain Res. 27: 113-129.

Goldberger, M. E., and M. Murray (1978) Recovery of movement and axonal sprouting may obey some of the same laws. In Neuronal Plasticity, C. Cotman, ed., pp. 73-96, Raven Press, New York.

Gordon, G., and M. G. M. Jukes (1964) Dual organization of the exteroceptive components of the cat's gracile nucleus. J. Physiol, (Lond.) 173: 263-290.

Hand, P. J., and T. Van Winkle (1977) The efferent connections of the feline nucleus cuneatus. J. Comp. Neurol. 171: 83-110.

Hazlett, J. C., R. Dom, and G. F. Martin (1972) Spino-bulbar, spino-thalamic and medial lemniscal connections in the American opossum, Didelphis marsupialis virginiana. J. Comp. Neurol. 146: 95-118.

Head, H. (1920) Studies in Neurology, Vol. 1, Oxford University Press, London.

Headley, P. M., A. W. Duggan, and B. T. Griersmith (1978) Selective reduction by noradrenalin and 5-hydroxytryptamine of nocioceptive responses of cat dorsal horn neurons. Brain Res. 145: 185-189.

Hodge, C. J., Jr., A. V. Apkarian, R. Stevens, G. Vogelsang, and H. J. Wisnicki (1981) Locus coeruleus modulation of dorsal horn unit responses to cutaneous stimulation. Brain Res. 204: $415-420$.

Holmquist, B., A. Lundberg, and O. Oscarsson (1960) Supraspinal inhibitory control of transmission to three ascending spinal pathways influenced by the flexion reflex afferents. Arch. Ital. Biol. 98: 60-80.

Johnson, K. O., and G. D. Lamb (1981) Neural mechanisms of spatial tactile discrimination: Neural patterns evoked by braille-like dot patterns in the monkey. J. Physiol. (Lond.) 
310: $117-144$.

Johnson, K. O., and J. R. Phillips (1981) Tactile spatial resolution. I. Two-point discrimination, gap detection, grating resolution and letter recognition. J. Neurophysiol. 46: 11771191.

Jones, M. B., C. J. Vierck, Jr., and R. B. Graham (1973) Linegap discrimination on the skin. Percept. Motor Skills 36: 563570.

Kitai, S. T., and J. Weinberg (1968) Tactile discrimination study of the dorsal column-medial lemniscal system and spino-cervico-thalamic tract in cat. Exp. Brain Res. 6: 234246.

Kruger, L., and A. D. Norton (1973) The Dorsal Column System of the Spinal Cord: Its Anatomy, Physiology, Phylogeny and Sensory Function. An updated review, Brain Information Service, Los Angeles.

Levitt, M., and R. J. Schwartzman (1966) Two-point tactile sensibility after spinal tractotomies in macaques. Anat. Rec. 154: 377.

Loomis, J. M., and C. C. Collins (1978) Sensitivity to shifts of a point stimulus: An instance of tactile hyperacuity. Percept. Psychophysics 24: 487-492.

McCreery, D. B., J. R. Bloedel, and E. G. Hames (1979) Effects of stimulating in raphe nuclei and in reticular formation on response of spinothalamic neurons to mechanical stimuli. J. Neurophysiol, 42: 166-182.

Mountcastle, V. B. (1961) Some functional properties of the somatic afferent system. In Sensory Communication, W. A. Rosenblith, ed., pp. 403-436, John Wiley and Sons, Inc., New York.

Myers, D. A., G. Hostetter, C. M. Bourassa, and J. E. Swett (1974) Dorsal columns in sensory detection. Brain Res. 70: 350-355.

Nelson, R. J., M. Sur, D. J. Felleman, and J. H. Kaas (1980) Representations of the body surface in postcentral parietal cortex of Macaca fascicularis. J. Comp. Neurol. 192: 611643.

Nijensohn, D. E., and F. W. L. Kerr (1975) The ascending projections of the dorsolateral funiculus of the spinal cord in the primate. J. Comp. Neurol. 161: 459-470.

Norrsell, U. (1966) The spinal afferent pathways of conditioned reflexes to cutaneous stimuli in the dog. Exp. Brain Res. 2: $269-282$.

Norrsell, U. (1980) Behavioral studies of the somatosensory system. Physiol. Rev. 60: 327-354.

Petit, D., and P. R. Burgess (1968) Dorsal column projection to receptors in cat hairy skin supplied by myelinated fibers. J. Neurophysiol. 31: 849-855.

Phillips, J. R., and K. O. Johnson (1981) Tactile spatial resolution. II. Neural representation of bars, edges and gratings in monkey primary afferents. J. Neurophysiol. 46: 1192-1203.

Pubols, L. M., and B. H. Pubols (1973) Modality composition and functional characteristics of dorsal column mechanoreceptive afferent fibers innervating the racoon's forepaw. J. Neurophysiol. 36: 1023-1037.

Randolph M., and J. Semmes (1974) Behavioral consequences of selective subtotal ablations in the postcentral gyrus of Macaca mulatta. Brain Res. 70: 55-70.

Rivot, J. P., A. Chaouch, and J. M. Besson (1980) Nucleus raphe magnus modulation of response of rat dorsal horn neurons to unmyelinated fiber inputs: Partial involvement of serotonergic pathways. J. Neurophysiol. 44: 1039-1057.

Roland, P. E. (1976) Astereognosis. Tactile discrimination after localized hemispheric lesions in man. Arch. Neurol. 33: 543550 .

Rustioni, A., N. L. Hayes, and S. O'Neill (1979) Dorsal column nuclei and ascending spinal afferents in macaques. Brain 102: 95-125.

Schwartz, A. S., E. Eidelberg, P. Marchok, and A. Azulay (1972)
Tactile discrimination in the monkey after section of the dorsal funiculus and lateral lemniscus. Exp. Neurol. 37: 582596.

Semmes, J., L. Porter, and M. C. Randolph (1974) Further studies of anterior postcentral lesions in monkeys. Cortex 10 : $55-68$.

Sprague, J. M., M. Levitt, K. Robson, C. N. Liu, E. Stellar, and W. W. Chambers (1963) A neuroanatomical and behavioral analysis of the syndromes resulting from midbrain lemniscal and reticular lesions in the cat. Arch. Ital. Biol. 101: 225-295.

Spreafico, R., N. L. Hayes, and A. Rustioni (1981) Thalamic projections to the primary and secondary somatosensory cortices in cat: Single and double retrograde tracer studies. J. Comp. Neurol. 203: 67-90.

Tapper, D. M. (1970) Behavioral evaluation of the tactile pad receptor system in the cat. Exp. Neurol. 26: 447-459.

Truex, R. C., M. J. Taylor, M. Q. Smythe, and P. L. Gildenberg (1965) The lateral cervical nucleus of cat, dog and man. J. Comp. Neurol. 139: 93-104.

Uddenberg, N. (1968) Functional organization of long, secondorder afferents in the dorsal funiculus. Exp. Brain Res. 4: $377-382$.

Vierck, C. J., Jr. (1966) Position sense after spinal tractotomies in macaques. Anat Rec. 154: 437.

Vierck, C. J., Jr. (1973) Alterations of spatio-tactile discrimination after lesions of primate spinal cord. Brain Res. 58: 6979.

Vierck, C. J., Jr. (1974) Tactile movement detection and discrimination following dorsal column lesions in monkeys. Exp. Brain Res. 20: 311-346.

Vierck, C. J., Jr. (1978a) Comparison of forelimb and hindlimb motoric deficits following dorsal column section in monkeys. Brain Res. 146: 279-294.

Vierck, C. J., Jr. (1978b) Somatosensory system. In Sensory Integration; Handbook of Behavioral Neurobiology, B. Masterton, ed., Vol. 1, pp. 249-309, Plenum Press, New York.

Vierck, C. J., Jr. (1978c) Interpretations of the sensory and motor consequences of dorsal column lesions. In Active Touch, G. Gordon, ed., pp. 139-159, Pergamon Press, Oxford.

Vierck, C. J., Jr. (1982) Plasticity of somatic sensations and motor capacities following selective interruptions of somesthetic inputs. In Changing Concepts of the Nervous System, A. R. Morrison and P. L. Strick, eds., pp. 113-165, Academic Press, Inc., New York.

Vierck, C. J., Jr., and M. B. Jones (1969) Size discrimination on the skin. Science 158: 488-489.

Vierck, C. J., Jr., and M. M. Luck (1979) Loss and recovery of reactivity to noxious stimuli in monkeys with primary spinothalamic chordotomies, followed by secondary and tertiary lesions of other cord sectors. Brain 102: 233-248.

Vierck, C. J., Jr., and R. Rand (1979) Localization of touch on glabrous skin following dorsal column lesions in a primate. Soc. Neurosci. Abstr. 5: 715.

Wall, P. D. (1970) The sensory and motor role of impulses traveling in the dorsal columns loward cerebral cortex. Brain 93: 505-524.

Wall, P. D., and W. Noordenbos (1977) Sensory functions which remain in man after complete transection of dorsal columns. Brain 100: 641-653.

Weinstein, S. (1968) Intensive and extensive aspects of tactile sensitivity as a function of body part, sex and laterality. In The Skin Senses, D. Kenshalo, ed., pp. 195-222, Charles C. Thomas Publishers, Springfield, IL.

Werner, G., and B. L. Whitsel (1968) Topology of the body representation in somatosensory area $I$ of primates. J. Neurophysiol. 31: 856-869.

Whitsel, B. L., L. M. Petrucelli, H. Ha, and D. A. Dreyer (1972) The resorting of spinal afferents as antecedent to the body 
representation in the postcentral gyrus. Brain Behav. Evol. 5: 303-341.

Willis, W. D. (1979) Supraspinal control of ascending pathways. Prog. Brain Res. 50: 163-174.

Willis, W. D., and R. E. Coggeshall (1978) Sensory Mechanisms of the Spinal Cord, Plenum Press, New York.

Willis, W. D., D. L. Trevino, and J. D. Coultier (1974) Responses of spinothalamic tract neurons to natural stimulation of the hindliunbs. J. Neurophysiol. 37: 358-372.

Zigler, M. J. (1935) The experimental relation of the two-point limen to the error of localization. J. Gen. Psychol. 13: 316332.

Zubeck, P. J. (1952) Studies in somesthesis. II. Role of somatic sensory areas I and II in roughness discrimination in cat. J. Neurophysiol. 15: 401-408. 